OSLa $\begin{aligned} & \text { Binyam Sisay Mendisu \& Janne Bondi Johannessen (eds.) Multilingual Ethiopia: Linguistic Chal- } \\ & \text { lenges and Capacity Building Efforts, Oslo Studies in Language 8(1), 2016. 201-218. (ISSN 1890- }\end{aligned}$
http://www. journals.uio.no/osla

\title{
SOME OBSERVATIONS ON HADIYYISA ORTHOGRAPHY
}

\author{
SHIMELIS MAZENGIA
}

\section{ABSTRAC T}

This study attempts to identify aspects of the orthography of Hadiyyisa (one of the Highland East Cushitic languages) that need to be improved and to suggest possible solutions to this. Accordingly, a short Hadiyyisa paragraph was dictated to and was written by randomly selected elementary, high school and first-year university students. The results showed that the students had a problem of distinguishing phonological quantity, that is, between simplex and geminate consonants as well as between short and long vowels. Consequently, representing geminates and long vowels as simple segments occurred frequently. Some aspects of orthographic inconvenience which require adjustments were encountered and solutions were suggested from the perspectives of regularity and economy. Yet another constraint was suggested in relation to the transferability of incompatible knowledge of Hadiyyisa to English. The performance of female students, especially at high school and university levels, was found to be lower than that of the male students and the study suggests that this needs to be further investigated.

\section{[1] INTRODUCTION}

This paper portrays the salient features of the Hadiyyisa orthography and discusses aspects that seem to require improvements. In addition, it tries to identify some areas that require attention so as to make the orthography more practical. It is by no means intended to be critical of the users of the orthography, but rather to draw the attention of those concerned towards tuning up the orthography for better writing and reading.

The language of the Hadiyya people, Hadiyyisa, belongs to the Highland East Cushitic group (a sub-group of the Cushitic family). In the 1970s and early 1980s, Hadiyyisa was one of the fifteen languages in Ethiopia with which a literacy campaign was conducted using the Ethiopic script. The latter is essentially a syllabary each of whose characters incorporates a consonant and a vowel. The system, however, manifests a feature of consonantary, because a character with the high (close) central vowel / $\dot{i} /$ may drop that vowel at the syllable-final position (e.g. *nibi > nib 'bee'). In 1994, the Latin script was adopted for Hadiyyisa, 
as was also the case with some other Cushitic languages of Ethiopia. Consequently, of the Cushitic group in the country, some use the Ethiopic script and others the Latin script. Currently, the Latin-based orthography of Hadiyyisa is in use especially in schools and at college, as well as university levels. At the elementary level (first cycle-grades 1-4), the language is used as a medium of instruction. At grade five level and above, it is offered as a subject. In Wachamo University, which is found in the vicinity of Hosa'na, the capital of the Hadiyya Zone, Hadiyyisa has become a field of specialization, as from the Ethiopian academic year 2007 (September 2014 - July 2015). In addition to making teachinglearning materials available at various levels, a bilingual dictionary, HadiyyisIngilliisis Saga'l Doona (Hadiyya-English Dictionary) has been published. In the dictionary, each Hadiyyisa entry is followed by an equivalent English word or phrase in parentheses. The meanings of the headwords, sometimes with additional explanations, are provided in Hadiyyisa. The dictionary was meant to be used by students and is, therefore, limited in distribution. For general readers, there is so far only one book, authored by Getahun Waatummo Doolle and entitled Hadiyy Heessechchaa Kobi'llishsha (Hadiyyisa Stories and Proverbs). Hadiyyisa is now one of the languages broadcast over the radio in the Southern Nations, Nationalities and Peoples Regional State (SNNPRS).

The orthography of Hadiyyisa, which is based on the Latin script, is alphabetic, where each grapheme (including each digraph) represents a phoneme. Like Hadiyyisa, for instance, English, is written in the Latin alphabet; but one cannot claim the orthography of the latter to be fully phonemic since all too often writing and pronunciation are at variance. In the English orthography, graphemes do not always represent phonemes. The section that follows presents the phonemes of Hadiyyisa.

\section{[2] PHONEMES}

There are 23 consonant phonemes in Hadiyyisa (Tadesse 2015: 20). However, the language uses additional five consonants for loanwords. As regards the inventory of vowel phonemes, the language has five short phonemic vowels, whose five long counterparts are also of phonemic value; thus, together constituting ten vowel phonemes. The two tables (in Figure 1 and 2) below provide respectively the inventory of the consonant and vowel phonemes of Hadiyyisa. In each column of FIGURE 1, the symbols on the left represent voiceless consonants, while those on the right voiced consonants. Symbols in parentheses represent consonants used for loanwords. 


\begin{tabular}{|c|c|c|c|c|c|c|c|c|c|c|c|c|}
\hline \multirow{2}{*}{\multicolumn{2}{|c|}{ Plosive }} & \multicolumn{2}{|c|}{ Bilabial } & \multicolumn{2}{|c|}{ Labiodental } & \multicolumn{2}{|l|}{ Alveolar } & \multicolumn{2}{|c|}{ Palatal } & \multicolumn{2}{|c|}{ Velar } & \multirow{2}{*}{$\begin{array}{l}\text { Glottal } \\
?\end{array}$} \\
\hline & & (p) & $\mathrm{b}$ & & & $\mathrm{t}$ & $\mathrm{d}$ & t5 & ds & $\mathrm{k}$ & & \\
\hline Nasal & & & $\mathrm{m}$ & & & & $\mathrm{n}$ & & (n) & & & \\
\hline Trill & & & & & & & $\mathrm{r}$ & & & & & \\
\hline Fricative & & & & $\mathrm{f}$ & (v) & $\mathrm{s}$ & $\mathrm{z}$ & . & (3) & & & $\mathrm{h}$ \\
\hline Approxi & & & $\mathrm{w}$ & & & & & & $\mathrm{y}$ & & & \\
\hline Lateral & proximant & & & & & & 1 & & & & & \\
\hline Ejective & $\begin{array}{l}\text { Plosive } \\
\text { Fricative }\end{array}$ & p' & & & & $\begin{array}{l}\mathrm{t}^{\prime} \\
\left(\mathrm{s}^{\prime}\right)\end{array}$ & & $t^{\prime}$ & & k & & \\
\hline
\end{tabular}

FIGURE 1: Consonant phonemes.

\begin{tabular}{|c|c|c|c|}
\hline & Front & Central & Back \\
\hline High & $\begin{array}{ll}\text { i } & \text { ii }\end{array}$ & & $\mathrm{u} \quad \mathrm{uu}$ \\
\hline Mid & e ee & & o oo \\
\hline Low & & aa & \\
\hline
\end{tabular}

FIGURE 2: Vowel phonemes.

In FIGURE 1, the five symbols in parentheses, as indicated above, represent sounds which occur in loanwords and are not typical to Hadiyyisa. Tadesse (2015: 21) points out that in loanwords, /p v $3 \mathrm{~s}$ / are usually replaced by /b f ds $\mathrm{t}$ / respectively. As regards the palatal nasal $/ n /$, although its occurrence in loanwords is attested, it is usually replaced by the alveolar nasal $/ n /$ (e.g., sanna 'Monday' < sanno (Amharic) 'Monday'). It does also occur in some ideophones (e.g., hanni 'bite' (orthographic representation hanynyi)); but its overall function in the language is not significant ${ }^{1}$. Hence, discounting the five borrowed consonants, Hadiyyisa has 23 consonant phonemes.

\section{[3] THE ALPHABET}

The Hadiyyisa alphabet, which represents the above consonant and vowel phonemes, consists of 33 graphemes. Of these, 28 are consonants and 5 are vowels (the graphemes of long vowels are not represented in the alphabet). Twenty-six of the graphemes of the alphabet correspond with the twenty-six letters of the English alphabet. The Hadiyyisa alphabet adds seven more, that is, six digraphs and the symbol of the glottal stop, which is represented by the apostrophe:

$<$ CH NY PH SH TS ZH ' >. In TABLE 1 below are the 33 graphemes of the Hadiy-

[1] Personal communication with Ato Samuel Handamo, Addis Ababa University, Department of Linguistics and Philology. 
yisa alphabet, in both majuscule and minuscule forms. Corresponding to each letter is given its name or how it is pronounced in the alphabetical list. The glottal stop, although in use since the adoption of the Latin alphabet, had not been considered a consonant until very recently. In the list below, I have put it, like Tadesse (2015: 17), at the end.

Unlike in English, $<\mathrm{x}>$ represents the ejective stop [ $\left.\mathrm{t}^{\prime}\right]$ in Hadiyyisa, as is also the case in some Ethiopian Cushitic orthographies, that is, in Oromo, Sidaama, Kambata and Gede'o. The glottal stop has only one form, <' >; it does not have allographic variants of majuscule and miniscule forms like the rest of the graphemes. Except for vowels $<\mathrm{E}, \mathrm{I}, \mathrm{O}, \mathrm{U}\rangle$, the names of all the consonants and that of vowel $<\mathrm{A}>$ terminate in the vowel sound $[-\mathrm{a}]$. As stated above, the relevance of five of the twenty-eight consonants, viz. < P, V, NY, TS ZH > (two simplex and three digraphs), is justified by their use for writing loanwords. 


\begin{tabular}{|c|c|c|}
\hline $\mathbf{N}^{\mathbf{o}}$ & $\begin{array}{c}\text { Grapheme } \\
\text { (Majuscule/ } \\
\text { Miniscule) }\end{array}$ & $\begin{array}{l}\text { Grapheme } \\
\text { Name }\end{array}$ \\
\hline 1 & $\mathrm{~A} \mathrm{a}$ & {$[\mathrm{a}]$} \\
\hline 2 & $\mathrm{~B} \mathrm{~b}$ & [ba] \\
\hline 3 & $\mathrm{Cc}$ & [ţa] \\
\hline 4 & $\mathrm{CH}$ ch & [ta] \\
\hline 5 & $\mathrm{D} \mathrm{d}$ & [da] \\
\hline 6 & $\mathrm{E} \mathrm{e}$ & {$[\mathrm{e}]$} \\
\hline 7 & $\mathrm{~F} \mathrm{f}$ & [fa] \\
\hline 8 & Gg & [ga] \\
\hline 9 & $\mathrm{H} \mathrm{h}$ & [ha] \\
\hline 10 & I i & [i] \\
\hline 11 & $\mathrm{Jj}$ & [dza] \\
\hline 12 & $\mathrm{~K} \mathrm{k}$ & {$[\mathrm{ka}]$} \\
\hline 13 & L 1 & [la] \\
\hline 14 & $\mathrm{M} \mathrm{m}$ & [ma] \\
\hline 15 & $\mathrm{~N} \mathrm{n}$ & [na] \\
\hline 16 & NY ny & [na] \\
\hline 17 & O o & [o] \\
\hline 18 & $P p$ & [pa] \\
\hline 19 & $\mathrm{PH}$ ph & [p'a] \\
\hline 20 & Q q & [k'a] \\
\hline 21 & $\mathrm{R} \mathrm{r}$ & {$[\mathrm{ra}]$} \\
\hline 22 & $\mathrm{~S} \mathrm{~s}$ & [sa] \\
\hline 23 & SH sh & {$[\mathrm{Ja}]$} \\
\hline 24 & $\mathrm{Tt}$ & [ta] \\
\hline 25 & TS ts & [s'a] \\
\hline 26 & $\mathrm{U} u$ & {$[\mathrm{u}]$} \\
\hline 27 & V v & [va] \\
\hline 28 & $\mathrm{~W} \mathrm{w}$ & [wa] \\
\hline 29 & $\mathrm{Xx}$ & [t'a] \\
\hline 30 & Y y & [ya] \\
\hline 31 & $\mathrm{Z} \mathrm{z}$ & [za] \\
\hline 32 & $\mathrm{ZH} \mathrm{zh}$ & [za] \\
\hline 33 & $\begin{array}{c}\text { ' (no } \\
\text { allograph) }\end{array}$ & [?a] \\
\hline
\end{tabular}

TABLE 1: The Hadiyyisa alphabet. 


\section{[4] HOW STUDENTS WRITE HADIYYISA}

As indicated above, the orthography of Handiyyisa is, as yet, only functional in educational establishments. In other words, it is not yet in use for administrative purposes and business. As a result, correspondences among government and private institutions are conducted in Amharic which is also the working language of the Federal State of Ethiopia.

To find out how students write Hadiyyisa using the Latin-based alphabet, thirty students were picked randomly in Hosa'na, the capital of the Hadiyya Zone, from (i) Ersa Adada Elementary School, (ii) Wachamo Preparatory School (grades 11 and 12) and (iii) Wachamo University. That is, ten students were picked from each educational establishment. They were respectively from grades $1-5$, grade 11 and university first year. of each group, five students were female and the other five male. The ten students of each group were asked to write a paragraph of thirty-six words in Hadiyyisa (see Appendix). The paragraph is based on a fable and orthographically consists of the consonant graphemes (including the representation of geminates) of the frequent phonemes in Hadiyyisa, except for $\langle J\rangle$. The other two missed graphemes, $\langle P H, Z\rangle$, are infrequent in distribution, including in the other Highland East Cushitic languages (Tadesse 2015: 22). As for the vowels of the language, all short and long forms are encountered repeatedly in the paragraph.

The paragraph was read to each group of students by a native speaker of the language very slowly and, whenever a student appeared to be in doubt, repeating words and sentences. Then, what each student wrote was assessed on the basis of errors made. The results are given below in three tables (see FIGURE 3, 4 and 5). Errors in identical words were counted only once. Similarly, errors related to not using capital letters were also considered as a problem and were counted only once. Errors with respect to missing or distorting words were counted on the basis of an average of two errors per word, that is, considering each word error as two spelling errors, since the average spelling errors in a distorted word were found to be two. The overall assessment of the students' performance was based on the following ten parameters:

(i) Misuse of capital letter (Cap.)

(ii) Hyper-gemination (Gem.+)

(iii) Hypo-gemination (Gem.-)

(iv) Consonant insertion (Cons.+) 
(v) Consonant missing or misrepresentation (Cons.-)

(vi) Hyper-lengthening (vowel) (Vl. L.+)

(vii) Hypo-lengthening (vowel) (Vl. L.-)

(viii) Vowel insertion (Vl.+)

(ix) Vowel missing or misrepresentation (Vl.-)

(x) Word missing or misrepresentation (Word)

Below, FIGURE 3, 4 and 5 present errors made by students at elementary, high school and university levels, respectively:

\begin{tabular}{|c|c|c|c|c|c|c|c|c|c|c|c|}
\hline & Cap. & Gem+ & Gem- & $\begin{array}{l}\text { Vwl } \\
\mathrm{L}^{+}\end{array}$ & $\mathrm{Vwl} \mathrm{L}^{-}$ & $\mathrm{Vwl}^{+}$ & $\mathrm{Vwl}^{-}$ & Cons + & Cons ${ }^{-}$ & Word - & Sum \\
\hline $\begin{array}{ll}1 & F\end{array}$ & 1 & 4 & 11 & 4 & 8 & 4 & 10 & -- & 6 & $8(4)$ & 56 \\
\hline $2 \mathrm{~F}$ & 1 & -- & 5 & - & 5 & - & 5 & -- & 4 & $44(22)$ & 64 \\
\hline $3 \mathrm{~F}$ & 1 & - & 10 & - & 7 & 1 & 15 & -- & 10 & $16(8)$ & 60 \\
\hline $4 \quad F$ & 1 & 3 & 3 & - & 1 & - & 2 & -- & 1 & -- & 11 \\
\hline $5 \mathrm{~F}$ & \multicolumn{8}{|c|}{ (A grade two girl unable to write) } & & $72(36)$ & 72 \\
\hline Sum & 4 & 7 & 29 & 4 & 21 & 5 & 32 & --- & 21 & $\begin{array}{l}140 \\
(70)\end{array}$ & 263 \\
\hline$\%$ & 1.52 & 2.66 & 11.03 & 1.52 & 7.98 & 1.9 & 12.17 & -- & 7.98 & 53.23 & $100 \%$ \\
\hline $6 \mathrm{M}$ & 1 & 1 & 19 & - & 15 & - & 13 & - & 9 & $2(1)$ & 60 \\
\hline $7 \mathrm{M}$ & 1 & -- & 19 & -- & 21 & 1 & 13 & -- & 7 & -- & 62 \\
\hline $8 \mathrm{M}$ & 1 & 5 & 12 & 2 & 16 & 1 & 2 & 1 & -- & -- & 40 \\
\hline $9 \mathrm{M}$ & 1 & - & 12 & 5 & 11 & - & 3 & - & - & - & 32 \\
\hline $10 \mathrm{M}$ & \multicolumn{9}{|c|}{ (A grade one boy unable to write) } & $72(36)$ & 72 \\
\hline Sum & 4 & 6 & 62 & 7 & 63 & 2 & 31 & 1 & 16 & 74 & 266 \\
\hline$\%$ & 1.5 & 2.26 & 23.31 & 2.63 & 23.68 & 0.75 & 11.65 & 0.38 & 6.02 & 27.82 & $100 \%$ \\
\hline Total & 8 & 13 & 91 & 11 & 84 & 7 & 63 & 1 & 37 & 214 & 529 \\
\hline$\%$ & 1.51 & 2.46 & 17.2 & 2.08 & 15.88 & 1.32 & 11.91 & 0.19 & 6.99 & 40.45 & $100 \%$ \\
\hline
\end{tabular}

FIGURE 3: Elementary level orthographic errors. $\mathrm{F}$ = female; $\mathrm{M}=$ male. 


\begin{tabular}{|c|c|c|c|c|c|c|c|c|c|c|c|}
\hline & Cap. & $\mathrm{Gem}^{+}$ & $\mathrm{Gem}^{-}$ & $V w l L^{+}$ & $V_{w l} L^{-}$ & $\mathrm{Vwl}^{+}$ & Vwl- & Cons $^{+}$ & Cons & Word & Sum \\
\hline \begin{tabular}{|ll}
1 & $F$
\end{tabular} & 1 & 3 & 13 & 3 & 14 & 2 & 7 & 1 & 6 & $10(5)$ & 60 \\
\hline $2 \mathrm{~F}$ & 1 & 1 & 13 & -- & 16 & 1 & 9 & -- & 6 & $6(3)$ & 53 \\
\hline $3 \mathrm{~F}$ & 1 & 2 & 11 & -- & 8 & 1 & 20 & - & 6 & $12(6)$ & 61 \\
\hline $4 \quad \mathrm{~F}$ & 1 & 2 & 20 & 5 & 15 & 2 & 2 & 2 & 3 & $2(1)$ & 54 \\
\hline $5 \mathrm{~F}$ & 1 & 1 & 10 & 4 & 16 & -- & 12 & -- & 7 & $4(2)$ & 55 \\
\hline Sum & 5 & 9 & 67 & 12 & 69 & 6 & 50 & 3 & 28 & 34 (17) & 283 \\
\hline$\%$ & 1.77 & 3.18 & 23.67 & 4.24 & 24.38 & 2.12 & 17.67 & 1.06 & 9.89 & 12.01 & $100 \%$ \\
\hline $6 \mathrm{M}$ & -- & 9 & 13 & 1 & 15 & 2 & 1 & - & -- & - & 41 \\
\hline $7 \mathrm{M}$ & 1 & 5 & 5 & 9 & 9 & 2 & 6 & 3 & 2 & -- & 42 \\
\hline $8 \mathrm{M}$ & 1 & 10 & 5 & -- & 3 & 1 & -- & 1 & - & - & 21 \\
\hline $9 \mathrm{M}$ & 1 & 9 & 10 & 1 & 10 & 2 & 1 & 1 & 1 & -- & 36 \\
\hline $10 \mathrm{M}$ & 1 & 1 & 10 & -- & 10 & 2 & 30 & - & 11 & $12(6)$ & 77 \\
\hline Sum & 4 & 34 & 43 & 11 & 47 & 9 & 38 & 5 & 14 & $12(6)$ & 217 \\
\hline$\%$ & 1.84 & 15.67 & 19.82 & 5.07 & 21.66 & 4.15 & 17.51 & 2.3 & 6.45 & 5.53 & $100 \%$ \\
\hline Total & 9 & 43 & 110 & 23 & 116 & 15 & 88 & 8 & 42 & 46 & 500 \\
\hline$\%$ & 1.8 & 8.6 & 22 & 4.6 & 23.2 & 3 & 17.6 & 1.6 & 8.4 & 9.2 & $100 \%$ \\
\hline
\end{tabular}

FIGURE 4: High school level orthographic errors.

\begin{tabular}{|c|c|c|c|c|c|c|c|c|c|c|c|c|}
\hline & & Cap. & Gem+ & Gem- & Vl L+ & Vl L - & $\mathrm{vl}^{+}$ & $\mathrm{vl}^{-}$ & Cons + & Cons - & Word - & Sum \\
\hline $1 \mathrm{~F}$ & $\mathbf{F}$ & 1 & -- & 2 & - & 1 & - & -- & -- & -- & -- & 4 \\
\hline $2 \mathrm{~F}$ & $\mathbf{F}$ & 1 & 7 & 3 & 1 & 5 & 2 & 1 & -- & 1 & - & 21 \\
\hline $3 \mathrm{I}$ & $\mathbf{F}$ & 1 & 6 & 7 & 9 & 16 & - & 1 & - & - & $4(2)$ & 44 \\
\hline $4 \quad \mathrm{~F}$ & $\mathbf{F}$ & -- & 8 & 4 & - & -- & - & - & - & -- & - & 12 \\
\hline $5 \quad \mathrm{I}$ & $\mathbf{F}$ & -- & 3 & 2 & - & -- & 1 & 1 & - & 1 & -- & 8 \\
\hline Sum & & 3 & 24 & 18 & 10 & 22 & 3 & 3 & 0 & 2 & $4(2)$ & 89 \\
\hline$\%$ & & 3.37 & 26.97 & 20.22 & 11.24 & 24.72 & 3.37 & 3.37 & 0 & 2.25 & 4.49 & $100 \%$ \\
\hline $6 \mathrm{~N}$ & M & -- & 3 & 6 & - & -- & -- & 1 & -- & -- & -- & 10 \\
\hline $7 \mathrm{~N}$ & M & 1 & 7 & 4 & - & 3 & -- & 1 & -- & -- & -- & 16 \\
\hline $8 \mathrm{~N}$ & $\mathbf{M}$ & -- & -- & 9 & 5 & 4 & - & -- & -- & -- & - & 18 \\
\hline $9 \mathrm{~N}$ & M & -- & - & 2 & - & 1 & -- & -- & -- & - & -- & 3 \\
\hline $10 \mathrm{~N}$ & & -- & - & 1 & - & - & - & -- & -- & -- & - & 1 \\
\hline Sum & & 1 & 10 & 22 & 5 & 8 & --- & 2 & --- & --- & --- & 48 \\
\hline$\%$ & & 2.08 & 20.83 & 45.83 & 10.42 & 16.67 & 0 & 4.17 & 0 & 0 & 0 & $100 \%$ \\
\hline Tota & & 4 & 34 & 40 & 15 & 30 & 3 & 5 & 0 & 2 & 4 & 137 \\
\hline$\%$ & & 2.92 & 24.82 & 29.2 & 10.95 & 21.9 & 2.19 & 3.65 & 0 & 1.46 & 2.92 & $100 \%$ \\
\hline
\end{tabular}

FIGURE 5: University level orthographic errors. 
Comparison of performance at the three levels shows that the highest number of errors was made by the elementary students, 529 [45.37\%] (see FIGURE 3), while that of the high school students is the next highest, 500 [42.88\%] (see FIGURE 4). By comparison, the number of errors of the university students, who had been teachers, is significantly lower, 137 [11.75\%] (see FIGURE 5). With respect to the average number of errors per student, that of the elementary is 53 [45.30\%] while that of the high school 50 [42.74\%] and that of the university 14 [11.97\%]. At the high school and university levels, the female students made more errors (13.2\% and $29.92 \%$ more than the male students, respectively) while at the elementary level it is the male students who made more errors by a narrow margin $(0.56 \%)$. As the preceding figures illustrate, at the high school level and, in a more pronounced manner at the university level, the performance of female students has been found to be low compared to that of the male students. Although the problem merits further investigation, it is considered to be a reflection of the burden of social responsibilities that teenage females and, more so, adult females are made to bear. The assumption is that the performance of female students, which is actually better than that of male students at the elementary level, though with a small margin, gradually decreases as they proceed to high school and university levels since, conversely, domestic chores as well as other family and social responsibilities increase.

The three most error-prone orthographic features at the elementary level were (from the most to the least prone): missing or distorting words, hypogemination, that is, failure to geminate consonants and hypo-lengthening, that is, failure to lengthen vowels. At the high school level the most error-prone orthographic features were: hypo-lengthening, hypo-gemination and vowel omission or substitution. Finally, those of the university level were: hypogemination as well as hyper-gemination and hypo-lengthening. The preceding results show that hypo-gemination and hypo-lengthening are the most common error types across the three educational levels. Decreasing or increasing quantity vis-à-vis consonants and vowels is not dependent on any pattern except for hyper-gemination of the digraph $<s h>$. The latter case is perhaps due to the influence of $<c h>$ which occurs word-medially in a geminated form except when followed by sonorants (Tadesse (2015: 23). Word missing or distortion essentially concerns long words with multiple morphemes (up to four).

TABLE 2 below presents the orthographic problems in the order of the first to the third most recurrent types at each educational level. The percentage of each error type at each level is relative to the percentage of the total number of errors. 


\begin{tabular}{ccccccc}
\hline & Elementary & \% & High School & \% & University & \% \\
\hline $\mathbf{1}$ & $\begin{array}{c}\text { Word } \\
\text { missing/distortion }\end{array}$ & 41 & Hypo-lengthening & 23 & $\begin{array}{c}\text { Hypo- } \\
\text { gemination } \\
\text { Hyper- }\end{array}$ & 29 \\
$\mathbf{2}$ & Hypo-gemination & 17 & Hypo-gemination & 22 & $\begin{array}{c}\text { gemination } \\
\text { Hypo- }\end{array}$ & 22 \\
\hline & Hypo-lengthening & 16 & $\begin{array}{c}\text { Vowel omission } \\
\text { /substitution }\end{array}$ & 18 & $\begin{array}{c}\text { lengthening } \\
\text { leming }\end{array}$ \\
\hline
\end{tabular}

TABLE 2: Hierarchy of recurrent orthographic errors.

We may generalize that the orthographic problem that occurs frequently at all three educational levels results from a failure to distinguish phonological quantity-that is, being unable to distinguish between simplex and geminate consonants, as well as between short and long vowels. Of the two problems of sound perception, that is, perceiving with increased quantity or with reduced quantity, the latter appears to be the most recurrent. In other words, the error type which is the most frequent in the use of the Hadiyyisa orthography could be characterized as reduction; that is, representing geminates with simplex consonants and long vowels with short ones.

FIGURE 6 presents the summary of errors in relation to gender at the elementary, high school and university levels. Missing or distorting words is the most recurrent error for the female students. By contrast, this error type is the third most recurrent for male students. On the other hand, for the male students, the main problem is a failure to geminate consonants. Notice that the three areas where most errors are committed (hypo-gemination, hypolengthening and word missing/distortion) are the same for both female and male students, though the hierarchy is different for each category.

\begin{tabular}{l|rrrrrrrrrrr}
\hline & Cap. & Gem. & Gem. & $V L_{L^{+}}$ & $V_{L^{-}}$ & $V^{+}$ & $V^{-}$ & Cons $^{+}$ & Cons- & Word & Sum \\
\hline Female & 12 & 40 & 114 & 26 & 112 & 14 & 85 & 3 & 51 & 178 & $\mathbf{6 3 5}$ \\
$\%$ & 1.89 & 6.3 & 17.95 & 4.09 & 17.64 & 2.2 & 13.39 & 0.47 & 8.03 & 28.03 & $\mathbf{1 0 0 \%}$ \\
Male & 9 & 50 & 127 & 23 & 118 & 11 & 71 & 6 & 30 & 86 & $\mathbf{5 3 1}$ \\
$\%$ & 1.69 & 9.42 & 23.92 & 4.33 & 22.22 & 2.07 & 13.37 & 1.13 & 5.65 & 16.2 & $100 \%$ \\
Total & $\mathbf{2 1}$ & $\mathbf{9 0}$ & $\mathbf{2 4 1}$ & $\mathbf{4 9}$ & $\mathbf{2 3 0}$ & $\mathbf{2 5}$ & $\mathbf{1 5 6}$ & $\mathbf{9}$ & $\mathbf{8 1}$ & $\mathbf{2 6 4}$ & $\mathbf{1 1 6 6}$ \\
$\%$ & $\mathbf{1 . 8}$ & $\mathbf{7 . 7 2}$ & $\mathbf{2 0 . 6 7}$ & $\mathbf{4 . 2}$ & $\mathbf{1 9 . 7 3}$ & $\mathbf{2 . 1 4}$ & $\mathbf{1 3 . 3 8}$ & $\mathbf{0 . 7 7}$ & $\mathbf{6 . 9 5}$ & $\mathbf{2 2 . 6 4}$ & $\mathbf{1 0 0 \%}$ \\
\hline
\end{tabular}

FIGURE 6: Orthographic errors in relation to gender. 


\section{[5] OTHER ISSUES TO NOTE}

In addition to the above discussed orthographic problems, there are other issues which seem to deserve proper attention. These are problems realized from the viewpoint of regularity, economy and negative transfer. Let us look at each one of them in turn.

\section{[5.1] Regularity}

It is generally assumed that one of the characteristics of a good orthography is regularity, because it eases the burden of applying various rules and facilitates learnability. From the perspective of this assumption, the varied forms of the graphemes of the class of ejectives in the Hadiyyisa orthography, $<\mathrm{cph} q$ ts $\mathrm{x}>$, could be regularized. They may respectively take the forms $<c^{\prime} p^{\prime} k^{\prime} s^{\prime} t^{\prime}>$, each consonant accompanied by the apostrophe as a diacritic.

As regards, especially, the grapheme $\langle x\rangle$, the fact that it is a simplex is a positive property, although the sound it has been made to represent (the alveolar ejective stop $\left./ t^{\prime} /\right)$, and the sound it is usually known for, for instance in the English orthography usually [ks], do not relate at all. It is true that in the orthographies of some other Cushitic languages too, as mentioned in section 3 above, it does represent the alveolar ejective stop $/ t^{\prime} /$. Furthermore, a study on the harmonization of Cushitic orthographies also recommends the use of the grapheme for the representation of the alveolar ejective stop (Qorro et al. 2014). Nonetheless, in some Cushitic languages it represents different sounds. For instance, in Afar it represents the alveolar implosive / $d /$, in Somali the voiceless pharyngeal fricative $/ \hbar /$, and in Konso the uvular fricative $/ \chi /$.

As indicated above, if regularity and simplicity are to be opted for, it is perhaps reasonable to replace $<\mathrm{x}>$ in Hadiyyisa with $<\mathrm{t}^{\prime}>$. Similarly, replacing $<\mathrm{c}$ ph ts $>$ with < c' p' s' $>$, which would be formally symmetrical with $<t^{\prime}>$, also seems sensible. Moreover, as discussed below, the replacement of $\langle\mathrm{c}\rangle$ by $\left\langle\mathrm{c}^{\prime}>\right.$ would also alleviate the encumbrance of $<\mathrm{ch}>$, especially in its geminated form $<$ chch $>$; that is, $<$ c $>$ would substitute for $<$ ch $>$ and the gemination would appear as $\langle\mathrm{cc}\rangle^{2}$. As for the ejective $\langle\mathrm{q}\rangle$, it may follow suit and could be replaced by $<\mathrm{k}^{\prime}>$. Nonetheless, taking account of its simplex form and its wider use, it may be retained. In fact, $<\mathrm{q}>$ is commonly used by most of the Ethiopian Cushitic languages for the velar ejective stop, except for Afar and Konso in whose orthographies it represents the voiced pharyngeal fricative $/ \varsigma /$, and the velar voiced implosive $/ \delta /$, respectively.

The recommended graphemes for the class of ejectives in Hadiyyisa, $<c^{\prime} p^{\prime} s^{\prime}$

[2] This is similar to Yri's suggestion for Sidaama, another Highland East Cushitic language (2004: 51). 
$t^{\prime}>$, might be objected to on the grounds that in each case the simplex consonant and the accompanying diacritic apostrophe (which is also used for the representation of the glottal stop) could possibly be pronounced separately. However, the problem does not seem to be a matter of concern for two reasons: first, the learners would be familiarized with the proposed graphemes in the manner, for instance, they are familiarized with the digraph $<s h>$. It was reported by some elementary Hadiyyisa teachers that there was almost no instance of learners pronouncing the constituents of $<s h>$ separately as $[s]$ and $[h]$, once they were familiarized with the diagraph. Secondly, there do not seem to be Hadiyyisa words in which the glottal stop follows the initial consonants of the proposed ejective digraphs; for example, where $[c]$ is followed by ['] and each is pronounced independently.

\section{[5.2] Economy}

This is a linguistic criterion which suggests that an analysis needs to be short and simple, in so far as the adequacy of the description or explanation aimed at can be ensured. Based on this criterion, the two subsections below propose the need for simplifying some digraphs and their consequent encumbered gemination in Hadiyyisa.

\section{Simplifying digraphs and gemination}

of the six digraphs in the Hadiyyisa alphabet, three, $<$ ch sh ph $>$, represent typical sounds of the language, whereas the other three, $<$ ny ts $z h>$, represent sounds of loanwords. The fact that the geminated forms of these digraphs overburden the orthography of the language is a matter of concern to those who wish to see the practical and effective use of the orthography - the more economical and simpler, the better. To deal with the problem, replacing the digraphs with simplex alternatives would be the best option. It is with this rationale that the replacement of $<\mathrm{ch}>$ by $<\mathrm{c}>$ has been suggested above. It is also in preference of simplicity that the replacement of $<$ ph and ts $>$ by $<$ p' and $\mathrm{s}$ ' $>$ has been recommended. With respect to the other three digraphs, $<$ sh ny $\mathrm{zh}>$, it does not seem possible to straightforwardly extract simplex or less encumbered alternatives from the alphabet to replace them. Therefore, retaining them as they are seems to be the only viable option.

The geminate form of $\langle c\rangle$ could simply be $\langle c c\rangle$, as indicated above, while those of $<p^{\prime} s^{\prime}$ ny $s h z h>$ may undergo reduction rather than simply doubling them as $<p^{\prime} p^{\prime}$ 's' nyny shsh zhzh $>$. Thus, the reduced alternative forms would appear as < pp' ss' $n n y^{3} s s h z z h>$. In the first two, a single apostrophe is used in-

[3] The reduction of nyny to nny and, based on the same principle, the reduction of the other Sidaama 
stead of two, while in the last three the second element of each digraph is reduced to one. Of course, there are still three symbols in each geminated form, but this is presumed to be a better option compared to four symbols in a geminate.

The other alternative for the representation of geminates of digraphs is to use each diagraph as it is. That is, a digraph is pronounced either as simple or as geminate depending on the pronunciation that the digraph represents in a word. This might create a phonetic problem for some readers of Hadiyyisa texts (especially beginners). Nonetheless, if the users of the orthography approve of it, it could be considered.

\section{Economy overriding}

In the earlier educational materials, such Hadiyyisa words as ga'nna 'address', wo'lla 'calves', ha'mma 'root of false banana (inset)', baa'yyaato 'give information', etc. appeared as such. However, of late, these words and their like appear with their geminate component simplified, that is, the double consonants are reduced to simplex - ga'na, wo'la, ha'ma, baa'yaato. The reason given for the alteration is the assumption that the language does not permit a cluster of three consonants (excepting gemination of digraphs). In his discussion of the restriction of co-occurrence, Tadesse (2015: 28ff.) points out that there is no word-final consonant cluster in Hadiyya, since words end in a vowel; and that there is no attestation of word-initial cluster. With respect to word-medial position, he indicates that the language allows a cluster of two consonants. However, as seen from the above words and similar ones, it appears that the language allows for a word-medial cluster of three consonants involving the glottal stop followed by a sonorant geminate $-2 \mathrm{C}^{1} \mathrm{C}^{1}$ ( $\mathrm{C}$ being sonorant). Therefore, the orthography of the language should have reflected this reality by representing the words in the latter fashion. Nonetheless, since there are no contrastive words to the ones with gemination of sonorants after the glottal stop, $\mathrm{CC}^{1} \mathrm{C}^{1}$, and giving value to economy, adopting the simplified representation of the words (reducing $\mathrm{CC}^{1} \mathrm{C}^{1}$ to $\mathrm{C}$ despite the pronunciation) seems acceptable.

\section{[5.3] Negative Transferability}

As indicated above, the graphemes of the Hadiyyisa alphabet and those of the English alphabet are essentially the same. However, some of the consonants

digraphs (though using the voiceless glottal fricative /h/ as a diacritic unlike the glottal plosive / $/$ in the present study) has been suggested by Yri. Similarly, the reduction of shsh to ssh in the present study has also been recommended by Yri for Sidaama but as sysy to ssy (considering sy for sh) (2004: $51)$. 
and all of the vowels demonstrate discrepancies in the ways they are pronounced in the orthographies of the two languages. While trying to pronounce them in English words, Hadiyyisa speaking children, especially those of the lower grades, tend to resort to the pronunciation of their own language. Among those simplex and digraphic consonants which manifest transferred distortion in pronunciation are $<\mathrm{c}$ ny ph $\mathrm{q} \mathrm{x}>$. As seen from the examples below, transferring the Hadiyyisa pronunciation to English would result in incomprehensibility.

$\begin{array}{lll}\text { English words } & \text { English pronunciation } & \text { Hadiyyisa pronunciation } \\ \text { cat } & {[k æ t]} & *\left[c^{\prime} a t\right] \\ \text { any } & {[\text { eni }]} & *[a j] \\ \text { physical } & {[\text { fizikal }]} & *\left[p^{\prime} y s i c^{\prime} a l\right] \\ \text { quit } & {[k w i t]} & *\left[k^{\prime} u i t\right] \\ \text { box } & {[b o k s]} & *\left[b^{\prime} t^{\prime}\right]\end{array}$

The example given below also illustrates a similar problem, especially with respect to vowels. That is, the vowels in the English words are made to assume Hadiyyisa pronunciation.

English words English pronunciation Hadiyyisa pronunciation

$\begin{array}{lll}\text { draw } & {[\text { dro: }]} & *[\text { draw }] \\ \text { keep } & {[\text { ki:p] }} & *[\text { keep }] \\ \text { one } & {[\mathrm{w} \Lambda \mathrm{n}]} & *[\text { 'one }] \\ \text { but } & {[\mathrm{b} \Lambda \mathrm{t}]} & *[\text { but }] \\ \text { kite } & {[\text { kait }]} & *[\text { kite }]\end{array}$

In view of the impact of negative transferability (sometimes also in the direction from English to Hadiyyisa), it is high time a solution was sought for the problem. In this regard, one helpful step, though not a complete solution, could be to let children first gain a degree of relative proficiency in their mother tongue rather than being introduced to English along with their mother tongue at the same time at a very early grade. The staggered introduction of languages could allow children and teachers to focus on one language at a time.

\section{[6] CONCLUSION}

As indicated from the outset, the objective of this study is to describe the main features of the Hadiyyisa orthography, to identify problems related to it as well as to the users, so as to make suggestions for improvements. Accordingly, the assessment made with regard to student orthographic performance revealed 
that there are, indeed, problems related to the orthography as well as to the users, that need to be addressed. Of the user problems considered here, the one related to gender may draw a particular interest. The fact that the performance of female students at high school and university levels is comparatively low needs to be further investigated. As indicated above, a provisional explanation could possibly be the relatively greater social responsibilities that teenage females and women are made to bear, which would perhaps not allow them to pay enough attention to their education.

Problems related to the use of the Hadiyyisa orthography are not limited to students. As seen from the performance of the students at university level, the problems are also found with teachers. The university students whose performance was assessed had been teachers with some training to teach the Hadiyyisa language. This is, therefore, an indication that the strategy to solve the problems related to the orthography and its use should primarily focus on teachers. Furthermore, making a standard dictionary available is also crucial.

Writing systems are usually subject to demands for improvement, that is, for simplicity, learnability and/or political reasons (Coulmas 2013: 108ff.). However, as underscored by Sebba (2007: 133), changing an established orthography is extremely difficult, since conservative elements who are in favour of maintaining the status quo resist any change. As regards the orthography of Hadiyyisa, it seems reasonable to make the necessary adjustments before aspects of the orthography which actually need to be improved get deeply entrenched and before users develop sentiments towards the status quo. In fact, as pointed out by Yri (2004: 12), improving orthography could be an on-going process. Otherwise, the option is living with the problems, as is the case, for instance, with English in which what is written and what is pronounced all too often do not correspond. However, that has meant, for instance, the creation of serious spelling problems for non-native users of English. Apart from realizing that improving orthography could be a continuous process, obtaining the consent of the stake holders is crucially important. All those who use an orthography-individuals as well as institutions-need to join in if improvements are to materialize. 
ABBREVIATIONS

$\begin{array}{llll}\text { 1SG } & \text { 1st person singular } & \text { ep } & \text { epenthesis } \\ \text { 2SG } & \text { 2nd person singular } & \text { GEN } & \text { genitive } \\ \text { 3SGF } & \text { 3rd person singular feminine } & \text { IPFV } & \text { imperfective } \\ \text { 3SGM } & \text { 3rd person singular masculine } & \text { INST } & \text { instrumental } \\ \text { AGR } & \text { agreement } & \text { INTR } & \text { interrogative } \\ \text { CNV } & \text { converb } & \text { NOM } & \text { nominative } \\ \text { COMP complementizer } & \text { PFV } & \text { perfective } \\ \text { COP copula } & \text { PROG } & \text { progressive } \\ \text { DAT dative } & & \end{array}$

\section{AC KNOWLEDGEMENTS}

This paper was funded by NORHED - Linguistic Capacity Building: Tools for Inclusive Development in Ethiopia - to which I am extremely grateful. I thank Dr. Zelealemam Leyew for his support in planning the data collection. I am also grateful to Ato Samuel Handamo, Dr. Tadesse Sibamo, Ato Derje Adane, and the Rondane (Norway) workshop participants for their valuable suggestions. Thanks also to the two anonymous reviewers for their constructive comments.

\section{REFERENCES}

Coulmas, Florian. 2013. Writing and Society. Cambridge: Cambridge University Press.

Getahun Waatummo Doolle. 2002 H.D (2009/10). Hadiyy Heessechchaa Kobi'llishsha (Hadiyyisa Stories and Proverbs). Addis Ababal: Nigd Mattemiya Dirijjit.

Hadiya Zone Education Desk. 1996 H.D. (2003/04). Hadiyyis-Ingilliisis Saga'l Doona (Hadiya-English Dictionary). Waachchamo.

Qorro, Martha, Shimelis Mazengia, Esayas Desta, Wondimu Gaga Gashe, Joseph Magway, and Fugich Wako. 2014. A Unified Standard Orthography for Cushitic Languages (Ethiopia, Somalia, Djibouti, Eritrea, Kenya, \& Tanzania), Monograph Series $\mathrm{N}^{\circ}$ 258. Cape Town: The Centre for Advanced Studies of African Society (CASAS).

Sebb, Mark. 2009. Spelling and Society: The Culture and Politics of Orthography around the World. Cambridge: Cambridge University Press.

Tadesse Sibamo Garkebo. 2015. Documentation and Description of Hadiyya (A Highland East Cushitic Language of Ethiopia). Unpublished PhD disserta- 
tion, Addis Ababa University.

Yri, Kjell Magne. 2004. Orthography and Phonology in Sidaamu Afoo (Sidamo). Journal of Ethiopian Studies, Vol. xxxvii $\mathrm{N}^{\circ} 1,41-55$.

APPENDIX I: A PARAGRAPH IN HADIYYISA

Daageechchii qamachchii afuutta'a attoorattonam daageechchi qamachchina "Saraxxi qorosho'i iibbadinne hooshe'akkamaare, xee'aa woga" yukko. Kan ammanenne qamachchi dabaraa, "Saraxxi qorosho'i iibbadinne xee'ooisa hinkidenne laqqeena xantitto." yaa xa'mmukko. Daageechchi odim dabaraa "Araat googinne higukkuuyyi wocookkoka macceesaateette.” yukkoo yakko'o.

Source: Onkis G/Kidaan. 1986 H.D (1993/94). “Hadiyyi Heessiinsee Kobi'llishshiinsee Hoffokam" (Hadiyyisa stories and proverbs). In Losa'n Caakka (The light of Education), Hosa'na, p. 22.

TRANSLATION OF THE PARAGRAPH

While a monkey and an ape were chatting, the monkey said to the ape, "Flatbread of sorghum with fresh milk is absolutely delicious." Then, the ape asked, "How do you know that flatbread of sorghum with fresh milk is delicious?" The monkey replied, "I heard it from passers by."

\begin{tabular}{|c|c|c|c|}
\hline $\begin{array}{l}\text { Daageechch-ii } \\
\text { monkey-CONJ }\end{array}$ & $\begin{array}{l}\text { qamachch-ii } \\
\text { ape-CONJ }\end{array}$ & $\begin{array}{l}\text { afuur-ta'a } \\
\text { sit-3SGF.CNV }\end{array}$ & $\begin{array}{l}\text { orar-tonam } \\
\text { t-3SGF.PROG }\end{array}$ \\
\hline $\begin{array}{l}\text { daageechch-i } \\
\text { monkey-NOM }\end{array}$ & $\begin{array}{l}\text { qamachch-ina } \\
\text { ape-DAT }\end{array}$ & & \\
\hline $\begin{array}{l}\text { "Saraxxi } \\
\text { sorghum.GEN }\end{array}$ & $\begin{array}{l}\text { qorosho'-i } \\
\text { flatbread-NOM }\end{array}$ & $\begin{array}{l}\text { iibbad-i-nne } \\
\text { fresh.milk-ep-INST }\end{array}$ & $\begin{array}{l}\text { hooshe'-akkamaare, } \\
\text { take.mouthful-when }\end{array}$ \\
\hline $\begin{array}{l}\text { xee'aa } \\
\text { delicious.CNV }\end{array}$ & $\begin{array}{l}\text { woga" } \\
\text { wonderful.cOP }\end{array}$ & $\begin{array}{l}\text { yukko. } \\
\text { said.he }\end{array}$ & \\
\hline
\end{tabular}

While a monkey and an ape were chatting, the monkey said to the ape, 
"Flatbread of sorghum with fresh milk is absolutely delicious."

$\begin{array}{llll}\text { Kan } & \text { ammane-nne } & \text { qamachch-i } & \text { dabar-aa, } \\ \text { this } & \text { time-INST } & \text { ape-NOM } & \text { return-CNV }\end{array}$

"Saraxxi qorosho'-i iibbad-i-nne xee'-oo'

sorghum.GEN flatbread-NOM fresh.milk-ep-INST delicious-COMP

hinkide-nne laqqeena xan-titto." yaa xa'mm-ukko.

how-INST know able-2SG.INTR say.CNV ask-3SGM.PFV

$\begin{array}{llll}\text { Daageechch-i } & \text { odim dabar-aa } & \text { "Araat-i } & \text { goog-i-nne } \\ \text { monkey-NOM } & \text { also return-CNV } & \text { passerby-NOM } & \text { road-ep-INST }\end{array}$

hig-ukk-uuyyi woc-ookko-ka maccees-aa-teette." yukko yakko'o.

pass-3SGM-PROG talk-3SG.IPFV-AGR hear.1SG-CNV-COP said.he said.they

Then the ape asked, "How do you know that flatbread of sorghum with fresh milk is delicious?'

The monkey replied, "I heard it from passers by."

CONTACT

Shimelis Mazengia

Department of Linguistics and Philology

Addis Ababa University

mazshim@yahoo.com 